Disease Comorbidity Index (RDCI). RACl consists of 31 comorbidities grouped into 11 categories: DAS $28>3.6$, local inflammation, smoking, tumors, systemic involvement, infection, vascular disease, bone health, mood, metabolic and cardiovascular disorders (score range $0-36$ ). RDCl consists of 11 comorbidities (categories according to ICD-10) and a formula to calculate it (range 0-9). For both indexes; higher score, greater comorbidity.

Results: In this cross-sectional study, 345 patients were evaluated, of which 176 were included, $85.8 \%$ of the patients were female and the mean age was $52.7 \pm 10.9$ years; $31.2 \%$ of the cases finished primary school, the median of disease duration was 9 years (1-40), the mean DAS28 $3.8 \pm 1.4$, and the mean CDAl $12.4 \pm 11.3 .52 .3 \%$ of the patients received treatment with glucocorticoids, $60.8 \%$ with NSAID, $60.2 \%$ with methotrexate, $39.2 \%$ with leflunomide, $17.6 \%$ with biologic DMARds and $5.6 \%$ with tofacitinib. $90.3 \%$ of the patients $(95 \% \mathrm{Cl}$ $84.8,94.3)$ presented some comorbidity measured by $\mathrm{RACl}$. The average score was $4.7 \pm 3.4$ and the most frequent comorbidity were: elevated DAS28 (40.9\%), dyslipidemia (38.1\%), AHT (36.4\%), prednisone $>5 \mathrm{mg} / \mathrm{d}$ in $31.8 \%$, endocrinopathies $19.3 \% .73 .3 \%$ of the patients had more than one comorbidity. Regarding $\mathrm{RDCl}, 47.2 \%$ of the cases presented some comorbidity with an average score of $0.95 \pm 1.3$; the most frequent were: $\mathrm{AHT} 36.4 \%$, lung disease $12.5 \%$ and diabetes $8 \%$. The oldest patients had more than one comorbidity (RACl), and also presented a higher HAQ score than those with only one $(p<0.0001)$. Higher $\mathrm{RACl}$ score was associated with higher CDAI $(p<0.001)$ and the use of glucocorticoids $(p=0.008)$.

Conclusion: The prevalence of comorbidities in RA by $\mathrm{RACl}$ was elevated $(90.3 \%)$ and $73.3 \%$ of the patients presented more than one comorbidity. The patients with the highest RACI score had higher disease activity and used glucocorticoids more frequently.

Disclosure of Interests: None declared

DOI: 10.1136/annrheumdis-2020-eular.5648

\section{FRI0604-HPR IS STRESS A TRIGGER FOR THE DEVELOPMENT OF SYSTEMIC LUPUS ERYTHEMATOSUS?}

Y. Soria Curi ${ }^{1}$, A. L. Barbaglia ${ }^{1}$, L. Gonzalez Lucero ${ }^{1}$, M. C. Bertolaccini ${ }^{1}$, H. R. Sueldo ${ }^{1}$, S. M. Mazza', M. L. Leguizamón ${ }^{1}$, G. V. Espasa' ${ }^{1}$, M. Pera ${ }^{1}$, V. I. Bellomio'. 'Hospital Ángel C. Padilla, Tucumán, San Miguel de Tucumán, Argentina

Background: Systemic Lupus Erythematosus (SLE) implies multifactorial psychological stress. Although stress has been spreaded as a "trigger" for the onset or flare of connective tissue diseases, there is controversial evidence of the association between stress and the diagnosis of SLE.

Objectives: To assess the frequency of stressors and vital events in patients with SLE and their relationship with the diagnosis.

Methods: A descriptive cross-sectional study was conducted. It were included patients over 18 years old with SLE diagnosis (ACR/SLICC criteria), attended in the Rheumatology Unit between May and August 2019; and 101 patients without any autoimmune disease. Demographic and disease-related variables were studied. The Holmes and Rahe Vital Events scale (43 questions) was used to evaluate vital events and measure the magnitude of stress that a person has experienced for a while and predict the onset of SLE. The sum of the scores indicates the magnitude of vital stress experienced by a person and the predisposition to acquire a disease. It was classified as: <150: small risk of illness due to stress; 150-299: moderate risk; and $\geq 300$ : high risk.

Results: 94 patients with SLE were included, of which $94 \%$ were women. The mean age was $36.3 \pm 10.3$ years. $41.9 \%$ of the cases had a family history of rheumatic disease and $31.2 \%$ of them were unemployed. During the year before the diagnosis of SLE, $48.4 \%$ of the patients suffered a stressful situation, the most frequent cause was the death of a close family member (44.1\%). Patients with SLE presented significantly higher stress scores than the healthy group (140 \pm 27 vs. $45.1 \pm 43, p=0.0001$ ); $54.8 \%$ of patients with SLE had a score $<150$; $23.65 \%$ between 150-299; and $10.75 \% \geq 300$. The number of patients with SLE was higher in the moderate and high risk categories $(>150)$ than the healthy group ( $34 \%$ vs. $2 \%, p=0.0001)$. When studying the Holmes and Rahe scale factors individually, patients with SLE had a higher frequency of situations related to: death of the couple $(p=0.029)$, death of a close relative $(p=0.0001)$, injury or personal illness $(p=0.006)$, change in living conditions $(p=0.0001)$ and poor relationship with the couple $(p=0.017)$.

Conclusion: Patients with SLE presented high frequency of stressful situations before diagnosis $(48.4 \%)$, and higher scores compared to the healthy group. The death of a close family member was the most frequent stressful event.

Disclosure of Interests: None declared

DOI: 10.1136/annrheumdis-2020-eular.5767

\section{FRI0605-HPR MORTALITY AND SURVIVAL IN PATIENTS WITH SYSTEMIC LUPUS ERYTHEMATOSUS IN ARGENTINA. A MULTICENTER STUDY ON BEHALF GESAR-LES}

M. C. Bertolaccini ${ }^{1}$, Y. Soria Curi ${ }^{1}$, L. Gonzalez Lucero ${ }^{1}$, G. V. Espasa ${ }^{1}$, A. L. Barbaglia ${ }^{1}$, H. R. Sueldo', M. L. Leguizamón ${ }^{1}$, S. M. Mazza' ${ }^{1}$, M. Santana ${ }^{1}$, L. M. Galindo ${ }^{1}$, R. Águila Maldonado ${ }^{2}$, M. García $^{2}$, D. Capelusnik ${ }^{3}$, R. Rojas Tessel $^{4}$, E. Picco ${ }^{4}$, M. E. Crespo Espindola ${ }^{4}$, R. Calvo ${ }^{5}$, S. Roverano ${ }^{5}$, M. Cosatti ${ }^{6}$, C. Pisoni ${ }^{6}$, P. Avila ${ }^{7}$, M. Micelli ${ }^{7}$, M. Hu ${ }^{8}$, L. Alascio ${ }^{7}$, C. Goizueta ${ }^{9}$, V. I. Bellomio ${ }^{1}{ }^{1}$ Hospital Ángel C. Padilla, Tucumán, San Miguel de Tucumán, Argentina; ${ }^{2}$ Hospital Interzonal General de Agudos General José de San Martín, La Plata, La Plata, Argentina; ${ }^{3}$ Psychophysical Rehabilitation Institute, Ciudad Autónoma de Buenos Aires, DQG, Argentina; ${ }^{4} \mathrm{Sr}$ Hospital del Milagro, Salta, Argentina; ${ }^{5}$ Provincial Hospital Dr. José María Cullen, EOZ, Argentina; ${ }^{6}$ University Institute CEMIC, EFA, Argentina; ${ }^{7}$ Hospital General de Agudos José María Ramos Mejía, ADC, Argentina: ${ }^{8}$ Hospital General de Agudos Jose María Penna, JLR, Argentina; ${ }^{9}$ Sanatorium July 9 SA, San Miguel de Tucumán, Argentina

Background: The mortality rate in patients with systemic lupus erythematosus (SLE) is 2-3 times higher than in the general population. However, survival in these patients has improved significantly and is currently $95 \%$ at 5 years according to different studies. Since the last 20 years, there are no new reports on this issue in Argentina.

Objectives: To analyze the factors associated with mortality, survival and causes of death in patients with SLE.

Methods: Longitudinal - multicenter study, in which 10 rheumatology centers of Argentina participated. Patients with SLE (ACR 1997 and / or SLICC 2012 criteria) with a minimum follow-up of 6 months monitored between January 2008 and December 2018 were included. Demographic, clinical, laboratory, therapeutic variables (treatments received during the evolution of the disease and within 60 days prior to death or last control); mortality, causes of death and survival at 5, 10 and 20 years were evaluated. Statistical analysis: descriptive statistics, Kaplan-Meier survival curves and Cox regression model.

Results: Three hundred and eighty two patients were included; $90 \%$ women and $82 \%$ mestizos. The mean of evolution time of SLE was $4.1 \pm 6.7$ years. The mean age at the last control or death was $37.2 \pm 12.7$ years, SLEDAI $3.2 \pm 4.2$ and SLICC $1.2 \pm 1.9$.

Mortality was $12 \%$ (95\% Cl [8-15]) and the causes of death were: Infections (27), cardiovascular disease (6), SLE activity (3), catastrophic antiphospholipid syndrome (2) and other causes (8). Using the variables associated with mortality in different Cox regression models, the variables that increased the risk of death significantly were: renal involvement (RR 3.3), cardiac involvement (RR 2.7), central nervous system involvement (RR 2.1), arterial thrombosis (RR 2.3), hyperlipemia (RR 2.4), number of infections (RR 1.2) and last SLEDAI (1.1).

The time of $\mathrm{HCQ}$ use greater than 36 months decreased the risk of death in this cohort by $40 \%$ ( $p$ 0.03). Prednisone (maximum dose and time) was not associated with mortality ( $\mathrm{pNS}$ ). When analyzing the last treatment and adjusting it for final SLEDAI, HCQ was a mortality protection factor (RR 0.4) while the use of cyclophosphamide alone or associated with prednisone was a risk factor for death (RR 5.2).

Significant differences were found when analyzing the causes of death according to the SLE evolution time ( $p$ 0.017): patients who died from infection had less evolution time (Me 2.25 years), than those who died due to cardiovascular causes (Me 10 years) or SLE activity (Me 15 years). In this cohort of patients, survival was $93 \%$ at 5 years, $88 \%$ at 10 years and $72 \%$ at 20 years.

Conclusion: Mortality in this series of patients was $12 \%$ and infection was the leading cause of death. The use of HCQ for a period greater than 36 months, decreased the risk of death $40 \%$.

Disclosure of Interests: None declared

DOI: 10.1136/annrheumdis-2020-eular.5870

\section{FRI0606-HPR REMISSION IN SYSTEMIC LUPUS ERYTHEMATOSUS, WHAT IS THE IMPACT ON ACCUMULATED DAMAGE?}

F. J. Hüttmann ${ }^{1}$, A. L. Barbaglia ${ }^{1}$, L. Gonzalez Lucero ${ }^{1}$, H. R. Sueldo ${ }^{1}$, M. C. Bertolaccini' ${ }^{1}$, S. M. Mazza', Y. Soria Curi ${ }^{1}$, M. L. Leguizamón ${ }^{1}$, G. V. Espasa ${ }^{1}$, L. M. Galindo ${ }^{1}$, M. Santana ${ }^{1}$, V. I. Bellomio ${ }^{1} .{ }^{1}$ Hospital Ángel C. Padilla, San Miguel de Tucumán, Argentina

Background: The objective of the treatment in rheumatic diseases is to achieved the remission or minimal disease activity of these patients. Previous studies in Systemic Lupus Erythematosus (SLE) showed that reaching remission had a positive impact on the prognosis of the disease.

Objectives: To determine the frequency of remission in a cohort of patients with SLE. 